\title{
Pedagogical Innovation within Facebook: A Case Study in Tertiary Education in Palestine
}

http://dx.doi.org/10.3991/ijet.v9i8.3805

\author{
K. Shraim \\ Palestine Technical University, Kadoorie, Palestine
}

\begin{abstract}
The proliferation of Facebook use among students and teachers has created a new learning culture by providing innovative ways for teachers to enable learners to engage actively in different learning activities. This paper investigates the potential use of the Facebook social network site to support faculty in implementing a social constructivist approach to facilitate student-centred learning. To alleviate problems arising from poor student engagement in large classes, 240 students from An-Najah National University, Palestine, enrolled in four sections of an undergraduate Educational Technology course, were encouraged to participate in a number of formative activities through Facebook. A mixed-methods case study approach was followed. The quantitative data from a questionnaire were analyzed and triangulated alongside the qualitative analysis of the content analysis of postings on the Facebook group page and classroom observation. The results show that the technological affordances of Facebook have a very valuable role in facilitating a constructive approach by faculty members. A majority of students showed a positive attitude to learning via Facebook, being provided with more opportunities to engage personally, communicate and work collaboratively, helping them to construct their own learning and develop 21st century skills for life and learning through social interaction. The key to the successful implementation of social networking is initiating institutional change to facilitate the dissemination of the new pedagogical culture.
\end{abstract}

Index Terms-Facebook, Digital native learners, Social constructivist approach, Social interaction, Student-centred learning.

\section{INTRODUCTION}

Twenty-first-century learners appear to differ from previous generations in expectations and learning styles. To meet their learning needs, there are many changes in teaching and learning methods to be assimilated and many opportunities to be explored and embraced. In response to this demand, higher education (HE) institutions in Palestine and internationally are challenged to embrace technology-enabled pedagogical innovation. This development requires significant changes to teaching and learning practices that will empower digital native learners to acquire skills in complex problem-solving, critically reflexive analytical thinking and succinct communication, in appropriately technology-assisted contexts [1]. More recently, the emerging Web 2.0 technologies (blogs, Twitter, podcasts, wikis, social network sites (SNSs), virtual worlds, video sharing and photo sharing) have evolved to show much promise of enhanced teaching and learning practices [2], [3], [4]. Since SNSs-especially Facebook - have become an integral part of the daily life of students in HE [4], [5], faculty are being encouraged to re- envision and revise their teaching approaches and to discover, implement and assess effective technologyenriched teaching and learning processes [1], [6], [7], [8], [9].

Higher education in Palestine is undergoing rapid expansion and diversification. Universities are using emerging technologies to create learning environments to stimulate their students and prepare them for lifelong learning. E-learning has recently grown rapidly across the HE sector in Palestine, where almost all universities are offering some type of online education [10]. An-Najah National University, one of the largest in Palestine, is pursuing its vision to improve the quality of $\mathrm{HE}$ through more learnercentred and technology-enhanced teaching and learning practices. In 2009, the university introduced e-learning to supplement face-to-face instruction and created its own platform to manage students' learning material, but there were technical problems in designing it, so Moodle was adopted to replace it in 2012. Crook and Harrison [11] state that HE institutions primarily use learning management systems (LMSs) such as Moodle and Blackboard that are focused on content delivery and not educational techniques, thereby reinforcing teacher-centred approaches to teaching and learning, and that LMSs have so far had a limited impact on pedagogy. Therefore, it is necessary to move e-learning beyond LMSs, to engage learners in the active use of Web 2.0 technologies for their self-governed, problem-based and collaborative activities [2], [7], [10]. More recently, many faculty members are leaning towards a flexible framework, integrating Web 2.0 into their teaching strategies. It is widely believed that Web 2.0, particularly SNSs such as Facebook, has the potential to foster a radical and transformational shift in teaching and learning towards a learner-centred approach by promoting autonomy and engagement in social networks that straddle multiple real and virtual learning spaces [2], [9], [12], [13].

Before 2011, the use of Facebook in Palestine was limited, because Facebook had removed Palestine as a network choice in 2006. Several Facebook campaigns were established in reaction to this delisting, including "If Palestine is removed from Facebook ... I'm closing my account", but despite the success of these campaigns, in 2008 there were only 42,720 people and 543 groups in the Palestine network on Facebook, which appeared to have little effect in organizing social action. Then the "Arab Spring" uprisings against regimes in Tunisia, Egypt and elsewhere in the Middle East relied heavily on social networks, especially Facebook [4]. Since the beginning of 2011, Facebook membership in the Arab region has more than doubled. By the end of December 2012, a quarter of 
PAPER

Pedagogical InNovation within Facebook: A CASE Study in Tertiary Education in Palestine

the four million Palestinians had accounts ${ }^{1}$. Facebook is used to support democracy and civic engagement [14]. Despite its widespread use as a social and political platform in Palestine, however, little attention has been given to integrating it into teaching and learning.

While the research literature on the importance of Web 2.0 technologies, particularly SNSs, has grown significantly in recent years, relatively little has been published on the educational affordances of Facebook for supporting faculty in changing their teaching strategies. Therefore, the main aim of this paper is to investigate the potential use of Facebook to support faculty in implementing a social constructivist approach to facilitate student-centred learning. It begins by presenting a review of the literature on the potential uses of Web 2.0 tools, and more specifically Facebook, in educational contexts, then describes the methodology used to integrate Facebook into the teaching of educational technology. After a discussion of pedagogical innovation within Facebook, it concludes with suggestions for future research.

\section{WEB 2.0 AND THE NEW LEARNING LANDSCAPE}

The emerging uses of Web 2.0 technologies for shaping the new learning landscape are gaining increased attention. Web 2.0 tools have the potential to meet the needs of $21^{\text {st }}$-century learners, who seek greater autonomy as well as collaborative networks and social interactive learning styles [2], [9], [12], [ 15], [ 16]. It is widely believed that the technological attributes and pedagogical affordances of Web 2.0, inspired and underpinned by social constructivist learning theory, signal a movement away from a teacher-centred paradigm to a more learner-centred one [2], [7], [9], [11], [12], [13], [ 15].

Social Constructivism establishes a number of principles to be accomplished during the development of an educational activity including constructive, active, significant, reflexive and collaborative [17]. Constructive means that the students have to modify their current knowledge schemes to integrate new information and acquire new knowledge. Active indicates that a total student participation is expected. Significant refers that learning has to be with a meaning, built from the conceptual structure the student already has. Reflexive shows that the student has to mirror his/her own experience on other students, making them experts in their own learning. Finally, to be Collaborative indicates that the studen learns from others by working together on the same objective, where each group member is a potential source of information [18].

According to Arquero-Montaño and Romero-Frías [19], Web 2.0 characteristics and SNSs in particular fit well the requirements of a social constructivist approach to education. SNSs is considered to be effective in developing essential skills, such as: creating knowledge, critically interpreting and analysing the socio-cultural context, working in groups and collaboratively, enhancing communication and interpersonal skills; sharing knowledge and information; and negotiating in horizontal contexts, avoiding hierarchical connections and exchanges of knowledge. To optimize the opportunities afforded by SNSs, technological development should be in parallel with evolving pedagogies [20]. The evolving pedagogy, framed as Pedagogy 2.0 [2]. Pedagogy 2.0 is the "concep-

\footnotetext{
Internet World Stats: http://www.internetworldstats.com/stats5.htm
}

tualization of teaching that is focused on participation in communities and networks for learning, personalization of learning tasks and production of ideas and knowledge" [2]. Mcloughlin and Lee [2] explain how the three main elements of pedagogy 2.0 principles are supported by SNSs. SNSs allow learners to access a wide range of resources, ideas and communities which they personally select as being appropriate to their own learning needs and preference. This personalization requires the learner to develop skills of self-regulation and autonomy. Secondly, learners participate in communities and global networks to share ideas, inquiry and problem-solving. Participation develops the skills of communication and collaborative working. Finally, productivity refers to how learners contribute to the social process of knowledge creation and generate new content, while their teachers act as facilitators of the learning process. This generates the skills of creativity, innovation and meta-cognition. McLoughlin and Lee [2] further argue that pedagogy 2.0 is not a matter of simply offering learners the technologies they are likely to use, but of creating a constructive learning environment to empower them with the skills needed for the $21^{\text {st }}$ century.

Although many SNSs are used in education, Facebook is by far the most popular and is gaining increased media attention. Facebook was created in 2004 and by the end of March 2012 had more than 901 million active users worldwide [16]. In fact, while it was not designed as an environment for constructing and managing learning experiences [9], it is important to recognize its educational affordances and potential value added for learning spaces. A number of researchers have investigated the use of Facebook in learning activities. The results indicate that academics are being encouraged to implement this technology for pedagogical reasons. For example, Facebook tools support effective collaboration and communication [16], thus enhancing students' engagement and motivating them to participate more actively in their own learning processes and to generate knowledge and inter-group cohesion [9], [21], [20]. Conversely, Wise et al. [24] argue that Facebook only promotes social engagement, having a limited role, if any, to play in increasing academic engagement. Others note that it allows students to design personalized learning environments [12], [16], promotes informal learning through social space and facilitates lifelong learning, so creating virtual communities of learners [25], [26], [27]. Rambe [3] further notes that Facebook postings serve as informal rubrics for assessing common student misconceptions and lack of understanding about learned content, thus potentially enhancing academics' ability to modify their teaching styles and to foreground complex concepts and issues.

Several studies (e.g. [21, 22]) have shown that incorporating Facebook into university courses promotes students' satisfaction with course delivery, as they are familiar and highly engaged with it. Roblyer et al. [23] compare HE faculty and student uses and perceptions of Facebook, reporting that students are much more likely than faculty to use Facebook and are significantly more open to the possibility of using similar technologies to support classroom work. While Facebook is well accepted by students, it remains unclear how academics would use it as a supplementary teaching tool. According to Rambe [3], much of the teaching presence was linked to didactic approaches which targeted student completion of tasks (assignments, 
elaboration of concepts and explanations of technical procedures in practical assignments), not the facilitation of peer-based discourse. Therefore, it is important for faculty to embrace this technology and discover ways to harness student engagement in meaningful and intellectually stimulated learning $[3,17]$.

\section{Methodology}

While many aspects of Facebook use could be investigated, this research focuses specifically on the following questions:

1. How can faculty use the technological attributes of Facebook to foster students' engagement, interaction and collaboration in a more constructivist and effective learning environment?

2. To what extent do the faculty engage students in the social space of Facebook? Do students' engagement demonstrate a superficial or in-depth level of participation? Do these patterns change over time?

3. What are students' opinions towards the new teaching approach using Facebook in their learning?

\section{A. Methods}

A mixed-methods case study approach, with concurrent triangulation methodology, was followed. A case study is an empirical inquiry that investigates a contemporary phenomenon within its real-life context through in-depth description and analysis of a bounded system from many different viewpoints [28]. In this case, the phenomenon or bounded system is confined to one of the faculty members with 240 (67\% female and 43\% male) undergraduate students in an Educational Technology course on using Facebook for learning in the context of An-Najah National University. Data were collected through a questionnaire, content analysis of wall posts and classroom observations.

A questionnaire about students' opinions towards the new teaching approach using Facebook in their learning was developed, based on literature related to integrating SNSs in the learning process. The questionnaire consisted of 24 items addressing the usefulness and challenges of using Facebook for educational purposes. Items were measured on a 5-point Likert scale. Content validity was provided by two faculty members in the School of Education reviewing the questionnaire. Positive feedback was received and some minor revisions were made to the instrument according to their suggestions. The Cronbach's alpha reliability coefficient of this scale was 0.87 .

Data on the contents of the Facebook page were coded according to the research questions by the researcher and four student moderators. Table I. summarizes the total number of messages posted during the semester by students and the instructor.

Students' contributions were evaluated for depth of processing. Factors indicating surface-level processing included making judgments without justification, repeating what had been said, answering polling, and asking irrelevant questions. In contrast, in-depth processing was apparent when users linked facts and ideas, offered new information, discussed the advantages and disadvantages of a situation, and made judgments supported by examples and/or justification (Table II). The content data were also analyzed quantitatively, including the nature of students' contributions: text-based newsfeed, visually-based newsfeed, private messages, real-time chatting, and answering polls (Table III).
TABLE I.

BI-WEEKLY PARTICIPATION DURING THE COURSE

\begin{tabular}{|c|c|c|c|c|c|c|}
\hline \multirow[t]{2}{*}{$\begin{array}{c}\text { Week } \\
\text { No. }\end{array}$} & \multirow[t]{2}{*}{$\begin{array}{c}\text { Total no. } \\
\text { of Mes- } \\
\text { sages }\end{array}$} & \multirow{2}{*}{$\begin{array}{c}\text { No. of } \\
\text { instruc- } \\
\text { tor's } \\
\text { messages }\end{array}$} & \multirow{2}{*}{$\begin{array}{c}\text { No. of } \\
\text { modera- } \\
\text { tors' } \\
\text { messages }\end{array}$} & \multirow{2}{*}{$\begin{array}{c}\text { No. of } \\
\text { students' } \\
\text { contribu- } \\
\text { tions }\end{array}$} & \multicolumn{2}{|c|}{$\begin{array}{l}\text { No. of partici- } \\
\text { pants (stu- } \\
\text { dents) }\end{array}$} \\
\hline & & & & & $\#$ & $\%$ \\
\hline W1-W2 & 654 & 57 & 44 & 553 & 134 & $56 \%$ \\
\hline W3-W4 & 536 & 52 & 49 & 435 & 147 & $61 \%$ \\
\hline W5-W6 & 602 & 41 & 69 & 492 & 165 & $69 \%$ \\
\hline W7-W8 & 673 & 33 & 63 & 577 & 187 & $78 \%$ \\
\hline W9-W10 & 850 & 28 & 58 & 764 & 211 & $88 \%$ \\
\hline Total & 3315 & 211 & 283 & 2821 & - & \\
\hline
\end{tabular}

The quantitative data from the survey were analyzed using descriptive statistical techniques and triangulated alongside the qualitative content analysis of postings on the Facebook group page and the classroom observation. The analysis was structured into four major themes representing the key elements of the constructivist approach: constructing knowledge, student participation, personalization and communication skills.

\section{B. Case Study}

In the academic year 2011-2012, 240 students from AnNajah National University, Palestine enrolled in four sections of an undergraduate Educational Technology course whose objective was to develop their competence in the use of educational technology for planning and delivering instruction. To alleviate problems arising from lack of student engagement in a large class with a small computer lab, students were encouraged to take a self-paced approach and to participate in a number of formative activities through Facebook.

The first week of the semester was dedicated to student orientation, explaining how Facebook should be used to complete the course activities. In the first face-to-face class, a short survey was conducted for each section, focusing on basic issues including whether students had Facebook accounts, how often they used this tool and for what purposes. A very high percentage $(90 \%)$ had accounts and they spent on average three hours per day using Facebook to socialize with their peers. Thus, the technology had a very high uptake among this group of students. It also transpired that most students who did not have Facebook accounts were females who felt that Facebook infringed the privacy required by Arab culture.

At orientation, the ethical, social and legal implications of the use of information technology were clearly explained to all students. Clear guidelines were set as to the use of names, not nicknames, and how often each student should engage in the activities outside face-to-face class time. As to how to participate, each student was required to make at least five posts at regular intervals during the semester, corresponding to $10 \%$ of the grade, with marks based on the quality and frequency of relevant postings.

A Facebook group was set up for each section. The groups were closed and students were invited to join them. Learners, even those with limited skills, joined the groups immediately and interacted with their peers, showing that Facebook is easy to use. To improve students' attitude towards the potential uses of Facebook in teaching and learning, students were asked in the initial activity to reflect on the socio-technical and pedagogical aspects of Facebook as an educational tool. Initially, 27 participants, 
including good students, were reluctant to use Facebook and expressed deep concern about distraction, timewasting and misuse of the medium.

Every two weeks, three students in each section were chosen to lead a discussion. They assigned different activities and asked the entire class to engage actively. Regular meetings were held with the faculty to ensure that these students were well prepared to facilitate the discussions, which began with open-ended questions. Multiple questions were created to keep the discussion exciting and stimulating, and to address the varied backgrounds and interests of learners. In addition, to ensure the inclusion of varied learning styles, students were encouraged to benefit from Facebook's strengths in posting their contributions in different formats. Since some female students remained reluctant to use Facebook for cultural reasons, eleven girls were permitted to use nicknames and/or send private messages to the teacher.

In the first activity, it was noticed that many students did not take the process seriously; within a short time, they clicked the Like button or posted messages randomly on the wall, which would indicate that they were frequently online but that they did not use this time to engage meaningfully. Some students posted broad topics and quite long personal comments into the Facebook group, while others were more focused in their contributions, posting good comments or profound questions that stimulated further conversation. Therefore, to encourage students to make positive posts, they needed consistent and meaningful feedback and face-to-face classroom discussion of a summary of the posts [29]. Throughout the process, teachers kept track of students' contributions, guiding them in broadening their range of knowledge through probing questions that helped them verbalize their understanding, or expanding on various posts, as well as sharing their own relevant knowledge.

At the end of the semester, all students were asked to complete a questionnaire to evaluate their learning experiences.

\section{Pedagogical inNovation Within Facebook}

\section{A. Constructing knowledge through social interaction}

A positive feature of Facebook is that it increases accessibility and breaks down academic and social boundaries; moving from an academic to a social space helps students to express themselves better, bringing together diverse ideas and a broad range of experiences [29]. Most learners $(88 \%)$ found the new teaching approach using Facebook is useful to produce their knowledge with their peers. However, it emerged that not all learners had immediately been able to embrace Facebook as a learning tool. A high percentage $(78 \%)$ indicated that they needed timely and effective support in understanding how to use it effectively. This finding indicates that while students were active participants through Facebook, they needed support to become critically engaged, self-reflexive producers of knowledge and understanding through social interaction. This result is consistent with the findings of Watson [30] and Rambe [3], who also suggest that the faculty should recognize the importance of rethinking their teaching methods and roles, becoming facilitators in designing stimulating learning environments.

Several methods were used during the course to enable learners to be creative and productive in their participa- tion: first, activities were designed to challenge students through varied questions adapted to the different learning styles, to help them construct the meaning of concepts through the social interaction of discussion at their own speed and in their own way. They were given examples of both excellent and bad contributions and asked to critique, interpret and challenge their thinking, thus directing them to a more analytical approach to making sense of and getting value from the content. They were also given a wide variety of resources and suggested materials that might lead them to a better quality of contribution. To make the students take the activity seriously and contribute more meaningfully, they were frequently reminded that their contributions would count towards their grades. To clear up misconceptions and ensure understanding, twelve polling quizzes were also developed by the facilitator during the semester.

Although this strategy was stressful for the faculty, most content was constructed by learners. The informal learning offered by the social space of Facebook helped faculty to stimulate creativity and enabled learners to create and generate ideas, concepts and knowledge, individually or in teams, using various communication tools. Another critical challenge was the feeling of confusion and disorientation for some students, who were used to strict, syllabus-directed lecture courses. Eleven per cent of participants wanted to know exactly what materials would be in the exam. They had difficulty in accepting that there might be more than one right answer-or none-and that perspectives and interpretations differed among class members.

Table II. shows that students' contributions became deeper over time. In the first two weeks of learning activities, $69 \%$ of their contributions were superficial, while by the end of week $10,58 \%$ were at a deep level of processing. This finding indicates that the quality of contributions improved with instructors' feedback and practice in critical and meaningful involvement in an activity. The data also reveal that half of the learners were either not sure or did not think they had enough interactivity with others. The participation pattern typically created a oneway interaction, because most students participated once and seldom a second or third time during a particular period. Some students, who always engaged actively and early, potentially missed out on later discussions. To create more effective learning spaces and to enhance twoway interaction, the faculty incorporated all the students' contributions on the Facebook page with face-to-face classroom discussions.

TABLE II.

STUDENTS' CONTRIBUTIONS DEPTH.

\begin{tabular}{|c|cc|cc|c|}
\hline Week no. & \multicolumn{2}{|c|}{$\begin{array}{c}\text { Surface } \\
\text { Contribution }\end{array}$} & \multicolumn{2}{|c|}{$\begin{array}{c}\text { In-depth Contri- } \\
\text { bution }\end{array}$} & Total \\
\hline Week1-Week2 & 384 & $69 \%$ & 169 & $31 \%$ & 553 \\
\hline Week3-Week4 & 287 & $66 \%$ & 148 & $34 \%$ & 435 \\
\hline Week5-Week6 & 315 & $64 \%$ & 177 & $36 \%$ & 492 \\
\hline Week7-Week8 & 309 & $54 \%$ & 268 & $46 \%$ & 577 \\
\hline Week9-Week10 & 318 & $42 \%$ & 446 & $58 \%$ & 764 \\
\hline
\end{tabular}


PAPER

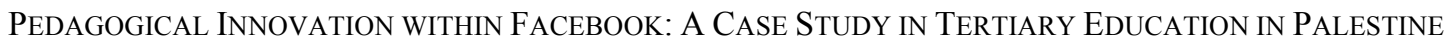

\section{B. Participation through collaboration}

When students are empowered to design their own learning activities, they can engage deeply in the learning process [31]. Almost all students were motivated to engage in one way or another and to take part in their learning. To get more students involved, every two weeks, three students were assigned to lead the discussion for each group. They took active roles in preparing and carrying out diverse learning activities. They also gave support to their peers, especially less confident students, encouraging them to participate in different activities according to their preferences. In face-to-face discussions, students were challenged to clarify their own contributions and to reflect on those of their peers. The point here is twofold: most students had a voice in deciding on the content (what to learn) and the pedagogy (how to learn), and were given opportunities to take responsibility for their learning and to play a leadership role in building their own learning journey, as well as the learning experiences of the class.

According to Llorens and Capdeferro [9], students become more engaged in debates and discussions when they have greater opportunities to work with a group of peers, in a classroom or virtually. One of the greatest advantages of Facebook is the creation of groups, offering different ways for learners and teachers to get together and engage in collaborative activity, knowledge-sharing and reflection through different interactive options: private messages, discussion boards and wall postings. It was noticed that when a YouTube video was uploaded, many students watched it together on Facebook and used the online chat feature to share their reactions while watching it.

The collaborative nature of Facebook encourages students to engage in critical thinking while working with their peers [32]. In the present study, however, working in groups initially proved to be a challenge. Many students expressed doubts about their ability to work in a team. Some were naturally less motivated than others; active and motivated students participated in the early discussions, while unmotivated ones were less likely to join in. It took time to persuade and encourage them to work together. This indicates the significant role of faculty in providing students with a better understanding of collaborative learning and communication. By the end of the process, many were impressed with what they had achieved collectively. As many as $72 \%$ of students were positive about the support and collegiality of their peers and felt that collaborative learning helped them to develop many skills that support lifelong learning, including critical analysis, constructive criticism of the work of their peers, negotiation, responsibility, teamwork and leadership. The findings suggest that in order to reap these benefits, students need to be prepared for meaningful collaboration and interaction with each other.

Another factor limiting collaboration is the scattering of discussions. Many learners $(54 \%)$ found it hard to follow all the posts in the drop-down comments, because these were not organized. This finding is similar to that of Wise et al. [24]. To enhance collaborative engagement, a variety of activities were designed, addressing different learning styles. Students were motivated to enrich the exchange of ideas and increase the potential of thought sharing and concept building in mixed media, picture and video sharing, and chatting. More motivated students, especially the moderators, were also active in organizing and summarizing posts in a radial, graphical, non-linear manner, using a free online mind-mapping tool, NovaMind, to stimulate face-to-face class discussion, during which most students, even the shyest, demonstrated that they felt confident in making contributions and reflecting on the contributions of others. Thus, they became more engaged in debates and arguments. Representing knowledge visually can be one of the most effective ways of constructing it, facilitating brainstorming and increasing participation in the discussion. This strategy enhances participation and interactivity, as students can also get help and support outside normal class hours from each other and from teachers.

Shifting the responsibility for learning to students puts them at the centre of the learning process, so this approach enables teachers to manage large diverse classes, acting as coaches and facilitators in designing interactive learning activities to motivate meaningful student engagement in both the content and process of learning.

\section{Personalization}

Facebook is a personal tool supporting self-governed and constructive processes [32]. It makes learning more adaptive to students' needs by offering a variety of options for how and when they engage with content, teachers and peers. This is the central attribute of pedagogy 2.0 , where learners can decide how to engage in personally meaningful learning [2]. During the course, students were able to engage in different learning activities at their own pace, based on their preferred learning approach. They chose from a variety of communication tools and contributed in various formats such as texts, images, videos and educational links. It was noticed that many students posted and viewed video and pictures easily and that they were more stimulated by information in videos than texts. For students who frequently failed or did poorly, quick surveys were developed using Facebook features, prompting them to participate in polling.

Sixty percent of students expressed concerns that they were distracted from concentrating on their studies as they switched to different resources. More than half also reported that they did not know how to choose and make decisions related to their personal learning needs. This finding is consistent with Kirschner and Karpinski [5], who found that Facebook users had poor timemanagement skills, spent less time studying and achieved lower academic results than non-users. Likewise, Rouis et al. [33] report that Facebook usage had a negative effect on students' achievement, but that they developed useful multitasking capabilities.

Since Palestinian students are used to traditional methods where the teacher is always in control, perhaps not all students felt that they were able to learn independently and take responsibility for their own learning [34]. Therefore, the challenge for faculty is to enhance learners' autonomy and enable them to become self-reliant and selfdirected by giving them opportunities to practise and exercise greater control over their own learning experience. A short-term programme may be insufficient for students to become autonomous, long-term efforts being preferable. Academics also need time and effort to collaborate with other faculty members to change their teaching methods, to take full advantage of Facebook's features and to create innovative learning approaches aligned with the needs of the students. 


\section{Communication skills}

Overall, students responded very positively to the developing of their communication skills through the Facebook learning environment: $78 \%$ felt that they were given an opportunity to practise and enhance the "netiquette" required to facilitate interaction in a social network; $75 \%$ were motivated to listen carefully and deepen their understanding of different perspectives by taking their learning beyond the boundaries of the classroom; $72 \%$ said that they had improved their language skills and academic writing; and $67 \%$ had a chance to talk about personal feelings and private experiences, getting to know each other via their online exchanges. Thus, Facebook has the potential to develop more dynamic learning communities. Since the course ended, students from the four groups have continued communicating with each other and with their teacher, forming virtual communities.

During the course, students had the opportunity to use various synchronous and asynchronous communication tools, supported by the Facebook environment. They held 290 real-time chat sessions with their peers and teachers, sent 198 private messages, answered polling 240 times, typed on the wall 965 times and uploaded 1128 videos and photos with their reflections (Table III).

Aside from these Facebook features, messages can also be accessed through mobile devices. Students connected with each other and worked together at any time in the social space of Facebook. However, one important theme emerging from this study is the poor communication skills of the students for explaining their thoughts and ideas and for developing a shared understanding of their learning experiences with their peers holding opposing points of view. Seventy-one percent preferred communicating via photos, videos and links rather typing text. It was noticed that when students used text messages, they were likely to be brief, verbally inadequate and grammatically inaccurate, habits which were carried over to other forms of writing. The brevity of texting precludes the establishment of deeper discussions that can contribute to the continued development of thinking skills. For teachers, this is a worrying and challenging process. Initially, much time and effort were spent on tracking students' contributions and giving them timely and meaningful feedback, checking spelling and grammar, telling them to stop using new language, even in less formal writing, giving examples of how to interact better with other individuals, handling conflict between groups and developing team skills.

TABLE III.

TYPE OF STUDENTS' CONTRIBUTIONS

\begin{tabular}{|c|c|c|c|c|c|c|}
\hline Week no. & $\begin{array}{c}\text { Total } \\
\text { no. of } \\
\text { contri- } \\
\text { butions }\end{array}$ & $\begin{array}{c}\text { Text- } \\
\text { based } \\
\text { wall } \\
\text { posting }\end{array}$ & $\begin{array}{c}\text { Visually- } \\
\text { based } \\
\text { wall } \\
\text { posting }\end{array}$ & $\begin{array}{c}\text { Private } \\
\text { message }\end{array}$ & $\begin{array}{c}\text { Real } \\
\text { time } \\
\text { chatting }\end{array}$ & $\begin{array}{c}\text { Answer } \\
\text { polling }\end{array}$ \\
\hline W1-W2 & 553 & 147 & 298 & 15 & 57 & 36 \\
\hline W3-W4 & 435 & 165 & 122 & 28 & 79 & 41 \\
\hline W5-W6 & 492 & 150 & 189 & 37 & 63 & 53 \\
\hline W7-W8 & 577 & 210 & 213 & 51 & 48 & 55 \\
\hline W9-W10 & 764 & 293 & 306 & 67 & 43 & 55 \\
\hline Total & 2821 & 965 & 1128 & 198 & 290 & 240 \\
\hline & & $34 \%$ & $40 \%$ & $7 \%$ & $10 \%$ & $9 \%$ \\
\hline
\end{tabular}

\section{CONCLUSION}

This paper has demonstrated the potential use of Facebook to support faculty in implementing a social constructivist approach, facilitating learner-centred learning. The technological affordances of Facebook have a very valuable role in facilitating a constructive approach by faculty members. A majority of students showed a positive attitude to learning via Facebook, being provided with more opportunities to engage personally, communicate and work collaboratively, helping them to construct their own learning and develop $21^{\text {st }}$-century skills for life and learning through social interaction. These are the principal traits of pedagogy 2.0, based on the social constructivist approach. Following this approach for the first time was stressful for the faculty; much time and effort were needed to empower students to engage meaningfully in their learning, because they were not prepared for active learning, but as long as it was constructive, teachers had something to build upon. Thus, a short-term view is not sufficient; we need to look for a long-term impact. To leverage the technological affordances of Facebook, all academic staff should recognize the importance of rethinking their teaching practices to create innovative learning approaches and align them with the needs of their students. The key to the successful implementation of social networking is initiating institutional change to facilitate the dissemination of the new pedagogical culture.

Although incorporating digital learning opportunities into HE has been shown to develop $21^{\text {st }}$-century skills through social interaction, the challenge for researchers is to evaluate how emerging technologies will enhance learners' achievements in different contexts.

\section{REFERENCES}

[1] Moore, A.H., Fowler, S.B. \& Watson, C.E. (2007). Active Learning and Technology: Designing Change for Faculty,Students, and Institutions, Educause Review, 42(5): 42-61.

[2] Mcloughlin, C. \& Lee, M. W. (2008). Future Learning Landscapes: Transforming Pedagogy through Social Software. Innovate Journal of Online Education, 4(5).

[3] Rambe, P. (2012). Critical discourse analysis of collaborative engagement in Facebook postings. Australasian Journal of Educational Technology, 28(2), 295-314.

[4] Weber, A.S. ( 2012). Considerations for Social Network Site (SNS) Use in Education. International Journal of Digital Information and Wireless Communications (IJDIWC) 2(4): 37-52

[5] Kirschner, P. \& Karpinski, A. (2010). Facebook and academic performance. Computers in Human Behavior, No 26, 1237-1245 http://dx.doi.org/10.1016/j.chb.2010.03.024

[6] Alexander, B. (2006). Web2.0: a new wave of innovation for teaching and learning? EDUCAUSE Review, 41(2), 32-44.

[7] Dalsgaard, C. (2006). Social software: E-learning beyond learning management systems. European Journal of Open, Distance and E-Learning. http://www.eurodl.org/. Accessed 20 October 2011.

[8] Alamoudi, G. (2009). Social networking in web-based learning solution. First International Conference in e-Learning and Distance Learning, March 16-18, 2009, Riyadh, KSA.

[9] Llorens, F. \& Capdeferro, N.(2011). Facebook's Potential for Collaborative e-Learning. Revista de Universidad y Sociedad del Conocimiento (RUSC), 8(2), 197-210.

[10] Shraim, K. (2012). Moving Towards e-Learning Paradigm: Readiness of Higher Education Institutions in Palestine. International Journal on E-Learning (IJEL), 11(4), 441-463.

[11] Crook, C., Fisher, T., Graber, R., Harrison, C., Lewin, C., Logan, C., Luckin, R., Oliver, M. \& Sharples, M. (2008). Web2.0 technologies for learning: The current landscape - opportunities, challenges and tensions. BECTA Research Report. http://partners.becta.org.uk/upload-dir/downloads/page_documen 
ts/research/Web2 technologies learning.pdf. Accessed 10 September 2011.

[12] Kuit, J. A., \& Fell, A.(2010). Web2.0 to Pedagogy 2.0: A SocialConstructivist Approach to Learning Enhanced by Technology. In R. Donnelly, J. Harvey \& K. O'Rourke (eds.), Critical Design and Effective Tools for E-Learning in Higher Education:Theory into Practice, 310-325.

[13] Pashnyak, T. (2011). Creating Facebook Communities of Practice: A Content Analysis. In Proceedings of World Conference on ELearning in Corporate, Government, Healthcare, and Higher Education 2011 (p. 1606). Chesapeake, VA: AACE.

[14] Talbot, D, (2012) Arab Spring. Technology Review , MIT

[15] Anderson, W. (2009). Web2.0 Technologies and Social Constructivist Practices in the Classroom: Possibilities and Challenges. In D. Jonassen and S. Land.P. (eds.), Theoretical Foundations of Learning Environments. https://sites.google.com/a/boisestate.edu/ edtech504/wsanderson. Accessed 13 September 2011.

[16] Melvin Ballera, M., Lukandu, I.A., Radwan, A (2013). Collaborative Problem Solving Using Social Network Media: Analyzing Student Interaction and its Impact to Learning Process. International Journal of Digital Information and Wireless Communications (IJDIWC) 3(1): 25-42

[17] Newman D., Griffin P. \& Cole M. (1989) The Construction Zone: Working for Cognitive Change in School. Cambridge University Press, New York

[18] Roschelle J. \& Teasley S. (1995) The construction of shared knowledge in collaborative problem solving: In ComputerSupported Collaborative Learning (ed. C. O‘Malley), pp. 69-97. Springer-Verlag, New York. http://dx.doi.org/10.1007/978-3-64285098-1 5

[19] Arquero-Montaño, J.L. \& Romero-Frías, E. (2013). Using Social Network Sites in Higher Education: an Experience in Business Studies, Innovations in Education \& Teaching International, 50(3): 238-249. http://dx.doi.org/10.1080/14703297.2012.760 772

[20] Bower, M., Hedberg, J. \& Kuswara, A. (2009). Conceptualising Web 2.0 enabled learning designs. In Same places, different spaces.Proceedings ascilite 2009. http://www.ascilite.org.au/conferences/auckland09/procs/bower.p df

[21] Irwin, C.,Ball, L. , Desbrow, B. \& Leveritt, M.(2012). Students' perceptions of using Facebook as an interactive learning resource at university. Australasian Journal of Educational Technology, 28(7), 1221-1232

[22] McCarthy, J. (2012). International design collaboration and mentoring for tertiary students through Facebook. Australasian Journal of Educational Technology, 28(5), 755-775.

[23] Roblyer, M.D., McDaniel, M., Webb. M., Herman, J. \& Witty, J.V. (2010). Findings on Facebook in higher education: A comparison of college faculty and student uses and perceptions of social networking sites. The Internet and Higher Education,13 (3) 134 140. http://dx.doi.org/10.1016/j.iheduc.2010.03.002

[24] Wise, L.Z., Skues, J. \&Williams, B.(2011). Facebook in higher education promotes social but not academic engagement. In G. Williams, P. Statham, N. Brown \& B. Cleland (Eds.), Changing Demands, Changing Directions. Proceedings ascilite Hobart. 1332-1342.
[25] Madge,C., Meek,J., Wellens, J. \& Hooley, T. (2009). Facebook, social integration and informal learning at university: 'It is more for socialising and talking to friends about work than for actually doing work'. Learning, Media and Technology, 34(2), 141-155. http://dx.doi.org/10.1080/17439880902923606

[26] Carbó, A.R. (2011). Online students initiate informal learning practices using social tools. eLearning Papers, 26. www.elearningpapers.eu. Accessed 25 January 2012

[27] Saikaew, K., Krutkam, W., Pattaramanon, R., Leelathakul, N., Chaipha, K.\& Chaosakul, A. (2011) . Using Facebook as a Supplementary Tool for Teaching and Learning, International Conference on eLearning Futures 2011, Auckland, New Zealand, Nov 30-Dec 1, 2011.

[28] Yin, R. (2003). Case study research: design and methods. Third edition, Sage Publication, London.

[29] Mobrand, E. (2011). Facebook for Teaching and Learning. Pedagogy in Technology, No. 1. National University of Singapore.

[30] Waston, K. (2011). Planning your online class. Learning To Teach Online Episodes. http://online.cofa.unsw.edu.au/sites/default/ files/episode-pdf/Planning class LTTO.pdf. Accessed 10 April 2012.

[31] Cameron, L. \& Tanti, M. (2011). Students as learning designers using social media to scaffold the experience. eLearning Papers, No 27. www.elearningpapers.eu. Accessed 20 January 2012

[32] Muñoz, C. \& Towner, T. (2009 ). Opening Facebook: How to Use Facebook in the College Classroom. Society for Information Technology and Teacher Education conference, Charleston, South Carolina.

[33] Rouis, S, Moez Limayem, M., \& Salehi-Sangari, E.(2011). Impact of Facebook Usage on Students'Academic Achievement: Role of self-regulation and trust. Electronic Journal of Research in Educational Psychology, 9(3).

[34] Shraim, K. \& Khlaif, Z. (2010). An E-Learning Approach to Secondary Education in Palestine: Opportunities and Challenges. Information Technology for Development, 16(3), 159-173 http://dx.doi.org/10.1080/02681102.2010.501782

\section{AUTHOR}

K. Shraim is an assistant professor in Educational Technology - Palestine Technical University - Kadoorie. Currently, K. Shraim is a Fulbright fellow at The University of California- Irvine, USA. She is one of the Founding Directors of the Center for Excellence in Learning and Teaching and the e-Learning Unit at An-Najah National University, Palestine. Her research interests revolve around promoting creative learning and innovative teaching in higher education, particularly in the area of technology-enhanced educational change include mobile learning, social online learning, the use of emerging technologies in education and training, and the use of ICT for Education for All. She has published many papers and presented workshops and seminars in many national and international conferences.

Submitted 26 April 2014. Published as re-submitted by the author 26 May 2014. 